\title{
Factors Affecting Hospital Choice Decisions: an exploratory study of healthcare consumers in Northern India
}

\author{
V Kamra, H Singh and K K De
}

\begin{abstract}
This study examines the factors affecting hospital choice decisions by patients for tertiary level healthcare services and the relationships of these factors with respondent demographics. It also categorises the decision makers involved in the selection of hospitals. Data were collected from in-patients of multispecialty hospitals located in northern India with the help of a structured questionnaire. Factor analysis, ANOVA and t-test techniques have been employed to analyse the data. The study has revealed that the factors that affect hospital choice decisions of patients are basic amenities, reputation and quality, building and infrastructure, ease and affordability, personal substances (experiences), responsiveness of services, recommendations and suggestions, clinical support,
\end{abstract}

privacy and information sharing, and range of services. The study has also revealed that various categories of respondent demographics, namely, age, gender, residence, education and monthly family income are significantly different statistically $(P<.05)$ with respect to the identified factors. It has been found that most of the time family members, doctors or a combination of family members and doctors make the decisions to choose the hospital. It has also been found that friends/ relatives and patients themselves choose the hospital in some cases.

Key words: consumer behavior; decision-making; healthcare; India, multispecialty hospitals; patients.

\section{Vishal Kamra \\ L M Thapar School of Management \\ Thapar University \\ Patiala, Punjab, India.}

\section{Harjot Singh}

L M Thapar School of Management

Thapar University

Patiala, Punjab, India.

\section{Kalyan Kumar De}

Amity Business School

Amity University

Noida, UP, India.

Correspondence:

vishalkamra@ymail.com

\section{Introduction}

Consumer behavior is the behavior of individuals in seeking, purchasing, using, evaluating and disposing of products and services in the marketplace. [1] Consumer buying behavior is an important aspect of overall consumer behavior. [2] Knowledge of it serves as a tool for marketers to understand what consumers actually buy, why, how, when and how often they buy it, and also how they consume and dispose of it. [3]

Tertiary level healthcare services refer to a third level of the healthcare system, in which specialised consultative care is provided to in-patients suffering from chronic health diseases. Multispecialty hospitals are centres of excellence for in-patient surgical procedures and offer comprehensive healthcare treatment across many specialties. [4]

Hospital choice factors are the service features considered by the patients to select one hospital in comparison to other. [5] Nowadays, patients are showing additional interest in choosing hospitals as well as in the treatment procedures. [6] Therefore, it is important to recognise the factors that affect patient hospital choice decisions as well as to categorise the decision makers involved in the selection. 


\section{The Indian healthcare system}

India has a population of 1.3 billion people residing in 29 states and seven union territories, 31 percent of which are situated in the northern part of the country that consists of seven states and two union territories. The government has traditionally provided healthcare services in India. In the early post-independence period, the Indian healthcare sector was suffering from a shortage of doctors and nurses, inadequate hospitals as well as a lack of modern medical equipment. In the 1980s, there was an approximate 30 percent decline in the use of both urban and rural public healthcare facilities. Thereafter, this sector has achieved tremendous growth, particularly in the last few decades. It is expected to become US\$280 billion sector by the end of 2020. [7]

\section{Defining the problem}

A number of studies have been conducted on hospital choice factors in developed countries; however few if any studies have examined the factors affecting hospital choice decisions of patients for tertiary level health diseases at multispecialty hospitals in an emerging economy. The present study is an attempt to bridge this gap in the literature. Its purpose is to explore the factors affecting hospital choice decisions by patients and to examine whether these factors are significantly different statistically with respect to various categories of respondent demographics or not, in the context of the services of multispecialty hospitals in India, an emerging economy. It also attempts to categorise the decision-makers involved in the selection of hospitals.

\section{Literature review}

\section{Hospital choice factors}

Consumers of healthcare services generally focus on attitudes and behaviors of hospital personnel, reputation and the hospital's image, quality of healthcare services and cleanliness of the facilities to select a hospital for the treatment. [8] Various factors which patients consider before selecting a hospital are nearness to home, availability of specialist doctors, latest technology, clean and hygienic environment, familiarity with hospital staff, past experience with hospital, cost of service, size of hospital and religious affiliation. [9]

Quality of service, a relative living in hospital town, finance, ease of transport, nearness to home, religion and connections with hospital staff are also the key factors in choosing a hospital. [10] Prior use of a hospital service, doctors' or friends' recommendations, courtesy of staff, new facilities, condition-specific reputation, nearness to home, quality of medical care and cost of service are also significant determinants of hospital choice decisions. [11]

The surroundings in which services are delivered have been found to influence hospital choice decisions, including the quality of medical staff, emergency and nursing care, the range of services, modern equipment, doctor-patient relationship, courteous employees, good surroundings, prior use of hospital, cost of care and availability of private rooms. [5] Various studies show that hospital choice decisions are more associated with convenient administrative procedures, quality of services, hospital image, cost of treatment, individual recommendation, waiting times at office visits and health insurance coverage. [12-14]

Patients have become more health conscious and they consider various factors like medical qualifications, cleanliness, infrastructure, payment mode, treatment time, technological capabilities, physical condition, image and reputation of the hospital, hospital size, nursing care and staff behavior, promptness of service, range of services, recommendations by doctor and relatives, waiting time, cost and location before selecting a hospital. [7, 15-19]

Most of the recently published studies have proposed that factors which affect hospital choice decisions of patients are reference by ambulance, physician's advice, family income, insurance type, quality of hospital services, employment of patient's family members in hospital, cost of services, punctuality of staff, publicity and advertisement, nearness of hospital, 24-hour outdoor services, quick admission process, machinery and technology, quality specialist doctors, confidential treatment record and payment modes. $[6,20,21]$

\section{Identifying the decision makers}

Patients themselves choose the hospitals for treatment except in emergency situations and mandatory hospitalisation. [22] Previous studies show that patients themselves decide in 22 percent of cases whereas they follow the advice of the doctor in 52 percent of cases. [5] In 62.5 percent of cases doctors decide, in 32.7 percent of cases patients and physicians make the decision and in 4.8 percent of cases patients themselves choose the hospital. [23] As per the findings of Daloglu, [24, p.20] 54 percent of the patients choose the hospital based on a doctor's recommendation, 33 percent decide themselves and 13 percent rely on their friends and relatives. Another study shows that, in 50 percent of cases doctors decide the hospital but in 42 percent of cases patients change their doctor in order to go for their preferred hospital. [15] 
Table 1: Disease distribution of respondents from each region

\begin{tabular}{|c|c|c|c|c|c|c|c|c|c|}
\hline & $\begin{array}{l}\text { KNEE-JOINT } \\
\text { REPLACEMENT }\end{array}$ & $\begin{array}{l}\text { SPINAL CORD } \\
\text { OPERATION }\end{array}$ & $\begin{array}{l}\text { HEART BY-PASS } \\
\text { SURGERY }\end{array}$ & $\begin{array}{l}\text { HEART STENT } \\
\text { IMPLANT }\end{array}$ & RENAL FAILURE & $\begin{array}{l}\text { HIP-JOINT } \\
\text { REPLACEMENT }\end{array}$ & $\begin{array}{l}\text { INTESTINE } \\
\text { PROBLEM }\end{array}$ & $\begin{array}{c}\text { LUNG } \\
\text { DISORDERS }\end{array}$ & TOTAL \\
\hline U.T. 1 & 33 & 33 & 37 & 51 & 25 & 24 & 7 & 13 & 223 \\
\hline State 1 & 64 & 26 & 12 & 11 & 33 & 34 & 4 & 8 & 192 \\
\hline State 2 & 36 & 52 & 33 & 11 & 0 & 0 & 15 & 0 & 147 \\
\hline U.T. 2 & 34 & 22 & 24 & 6 & 2 & 5 & 11 & 10 & 114 \\
\hline State 3 & 4 & 9 & 13 & 10 & 13 & 3 & 4 & 8 & 64 \\
\hline State 4 & 9 & 13 & 14 & 3 & 1 & 0 & 9 & 3 & 52 \\
\hline State 5 & 1 & 3 & 13 & 2 & 5 & 6 & 3 & 5 & 38 \\
\hline State 6 & 11 & 6 & 11 & 0 & 0 & 1 & 0 & 0 & 29 \\
\hline State 7 & 5 & 8 & 5 & 0 & 0 & 5 & 0 & 1 & 24 \\
\hline Total & 197 & 172 & 162 & 94 & 79 & 78 & 53 & 48 & 883 \\
\hline
\end{tabular}

\section{Methodology}

The primary objective of the study was to identify the factors affecting hospital choice decisions of patients and to examine whether these factors are significantly different statistically with respect to patient demographics. Another objective was to categorise the decision makers involved in the selection of hospitals. Patients in multispecialty hospitals, particularly suffering from tertiary level health diseases, based in northern India comprised the population for the study. Patients suffering specifically from eight types of tertiary level health diseases were considered as respondents. Table 1 shows the disease-wise distribution of respondents from each region.

Considering the awareness level of the respondents, a set of 42 questions, based on a self-developed scale, was administered. They were requested to rate the importance of factors affecting their hospital choice decisions on a five-point importance scale ( 1 = Not At All Important, 2 = Unimportant, 3 = Neither Important Nor Unimportant, $4=$ Important, 5 = Extremely Important). Various demographic variables were also considered to understand the diverse behavior of respondents. Table 2 shows the demographic criteria and health insurance break-up of respondents.

The study instrument was pre-tested on a sample of 100 respondents. It was found to be reliable with a value of 0.72 of Cronbach's alpha and valid with the values more than 0.40 of factor loadings for each statement. On the basis of convenience sampling, 1000 questionnaires were distributed and 883 fully-filled responses were received.
There was a risk of some bias in this technique; however, it allows researchers to formulate theories quickly. Data were collected between March and August 2014 and were analysed by applying exploratory factor analysis, one way ANOVA and two-tailed t-test (at five percent significance level) with the help of SPSS ${ }^{\circledR} 16.0$.

Measures of sample adequacy such as Kaiser-Meyer-Olkin (.70) and Bartlett's Test of Sphericity (approx chi-square 21313.85, degrees of freedom 861, significance .00) show that factor analysis can be applied. Principal component analysis with varimax rotation method was used for extracting the factors. Statements with factor loadings greater than value 0.40 were considered. Factors with an Eigen value of one or more were extracted. All the factors were named after discussion with other researchers and on the basis of existing literature. ANOVA and t-test techniques were applied to check the differences between Mean Score (MS) of each category of respondent demographics and the identified factors. The factors were tested individually with respect to all categories of respondent demographics. MS of each demographic category was compared and post hoc analysis was performed on independent demographic variables containing more than two categories.

\section{Results}

Ten factors were extracted, which cumulatively explained 65 percent of the total variance. Statistically significant differences $(P<.05)$ were found among the various categories of respondent demographics with respect to these factors. 
Table 2: Demographic criteria and health insurance break-up of respondents

\begin{tabular}{|c|c|c|}
\hline DEMOGRAPHIC CRITERIA AND HEALTH INSURANCE & NO. OF RESPONDENTS ( $\mathrm{N}=883$ ) & PERCENTAGE (\%) \\
\hline $\begin{array}{l}\text { AGE } \\
\text { Up to } 20 \text { Years } \\
21-35 \text { Years } \\
36-50 \text { Years } \\
\text { More than } 50 \text { Years }\end{array}$ & $\begin{array}{r}52 \\
159 \\
256 \\
416\end{array}$ & $\begin{array}{l}05.9 \\
18.0 \\
29.0 \\
47.1\end{array}$ \\
\hline $\begin{array}{l}\text { GENDER } \\
\text { Male } \\
\text { Female }\end{array}$ & $\begin{array}{l}591 \\
292\end{array}$ & $\begin{array}{l}66.9 \\
33.1\end{array}$ \\
\hline $\begin{array}{l}\text { MARITAL STATUS } \\
\text { Married } \\
\text { Unmarried }\end{array}$ & $\begin{array}{r}787 \\
96\end{array}$ & $\begin{array}{l}89.1 \\
10.9\end{array}$ \\
\hline $\begin{array}{l}\text { RESIDENCE } \\
\text { Metro City } \\
\text { Non Metro City } \\
\text { Semi Urban Area } \\
\text { Rural Area }\end{array}$ & $\begin{array}{l}149 \\
423 \\
204 \\
107\end{array}$ & $\begin{array}{l}16.9 \\
47.9 \\
23.1 \\
12.1\end{array}$ \\
\hline $\begin{array}{l}\text { EDUCATION } \\
\text { Post Graduation and Above } \\
\text { Graduation } \\
\text { Diploma } \\
\text { Class XII or Below }\end{array}$ & $\begin{array}{r}194 \\
168 \\
62 \\
439\end{array}$ & $\begin{array}{l}22.0 \\
19.0 \\
07.0 \\
52.0\end{array}$ \\
\hline $\begin{array}{l}\text { OCCUPATION } \\
\text { Government Employee } \\
\text { Private Employee } \\
\text { Businessmen } \\
\text { Dependent }\end{array}$ & $\begin{array}{r}62 \\
141 \\
263 \\
417\end{array}$ & $\begin{array}{l}07.0 \\
16.0 \\
29.8 \\
47.2\end{array}$ \\
\hline $\begin{array}{l}\text { MONTHLY FAMILY INCOME } \\
\text { Up to Rs. } 25,000 \\
\text { Rs. } 25,001 \text { to Rs. } 50,000 \\
\text { Rs. } 50,001 \text { to Rs. } 75,000 \\
\text { Rs. } 75,001 \text { to Rs. } 1,00,000 \\
\text { More than Rs. } 1,00,000\end{array}$ & $\begin{array}{r}93 \\
136 \\
319 \\
224\end{array}$ & $\begin{array}{l}10.5 \\
14.3 \\
36.1 \\
25.4\end{array}$ \\
\hline $\begin{array}{l}\text { HEALTH INSURANCE } \\
\text { Yes } \\
\text { No }\end{array}$ & $\begin{array}{l}114 \\
769\end{array}$ & $\begin{array}{l}12.9 \\
87.1\end{array}$ \\
\hline
\end{tabular}

\section{Factor analysis \\ Basic amenities}

This was the first factor affecting hospital choice decisions of patients for tertiary level healthcare services. Five service features that significantly load on this factor are availability of facilities like water, electricity, wash rooms and fans, approachable pharmacy, canteen and cafeteria facility, provision for the parking of vehicles and sufficient waiting areas. The eigen value of this factor was found to be 3.568 and explained the variance of $8.496 \%$. Findings of other studies also show that basic amenities are the considerable determinants of hospital choice decisions. [18]

\section{Reputation and quality}

This was the second factor affecting hospital choice decisions of patients. Six service features which significantly load on this factor are the brand name of the hospital, the reputation of doctors associated with the hospital, general image of the hospital in society, years of existence of the hospital, religious/cultural preference and quality specialist doctors. The eigen value of this factor was found to be 3.447 and explained the variance of $8.208 \%$. Various studies also show that these service features are significant determinants of hospital choice decisions. [19] 


\section{Building and infrastructure}

This was the third factor affecting hospital choice decisions of patients. Six service features that significantly load on this factor are the latest equipment and facilities in the operation theatre, modern living room facilities, hospital building and infrastructure, availability of latest and hi-tech equipment and number of the rooms and beds. The eigen value of this factor was found to be 3.226 and explained the variance of $7.681 \%$. Previous studies also show that these service features are important determinants of hospital choice decisions. [6]

\section{Ease and affordability}

This was the fourth factor affecting hospital choice decisions of patients. Six service features that significantly load on this factor are the cost of hospital services, ease of approaching the hospital and getting appointments, proximity of the hospital to your place of residence, tie up of the hospital with the insurance companies and timing of the OPD services. The eigen value of this factor was found to be 3.128 and it explained the variance of $7.448 \%$. Findings of various studies also support these findings. [16]

\section{Personal substances (experiences)}

This was the fifth factor affecting hospital choice decisions of patients. Four service features that significantly load on this factor are any friend/relative who is working in the hospital, awareness about a disease and its treatment process, severity and duration of the illness and your previous experience with the hospital. The eigen value of this factor was found to be 2.736 and it has explained the variance of $6.513 \%$. Previous studies also support these service features as determinants of hospital choice decisions. [20]

\section{Responsiveness of services}

This was the sixth factor affecting hospital choice decisions of patients. Three service features that significantly load on this factor are the punctuality and courteous behavior of nursing staff, quick administrative procedures, speed in the delivery of services and waiting time to get treated. The eigen value of this factor was found to be 2.537 and has explained the variance of $6.040 \%$. Findings of various studies also support these findings. [7]

\section{Recommendations and suggestions}

This was the seventh factor affecting hospital choice decisions of patients. Three service features that significantly load on this factor are a recommendation by someone who has already had the treatment, a recommendation by your friends/relatives and by your local doctor. The eigen value of this factor was found to be 2.369 and explained the variance of $5.640 \%$. Previous studies also show that these service features are relevant determinants of hospital choice decisions. [11]

\section{Clinical support}

This was the eighth factor affecting hospital choice decisions of patients. Two service features that significantly load on this factor are provision for the ambulance, blood bank and laboratories. The eigen value of this factor was found to be 2.173 and explained the variance of $5.174 \%$. Findings of various studies also support these findings. [5]

\section{Privacy and information sharing}

This was the ninth factor affecting hospital choice decisions of patients. Two service features that significantly load on this factor are privacy and dignity during treatment and sharing of information with patients. The eigen value of this factor was found to be 2.151 and it has explained the variance of $5.123 \%$. Previous studies also support these service features as determinants of hospital choice decisions. [21]

\section{Range of services}

This was the tenth factor affecting hospital choice decisions of patients for tertiary level healthcare services. Five service features that significantly load on this factor are the availability of emergency, general health and specialised healthcare services, service packages like full body checkup and having all the medical departments. The eigen value of this factor was found to be 2.054 and it has explained the variance of $4.890 \%$. Findings of various studies also support these service features as determinants of hospital choice decisions. [15]

\section{ANOVA and t-test}

\section{Age}

Age has a positive effect on hospital choice decisions of patients. Korgaonkar et al [25] have observed the importance of prior experience in the minds of aged patients. For this study also, respondents in the age group of 'more than 50 years' reported remarkably higher importance (MS=4.79) with respect to 'personal substance (experience)' in comparison to other categories. The respondents of '21-35 years' category showed relatively lower importance (MS=3.96). This may be due to the severity and duration of illness and the patients' previous experience of the same hospital. The respondents of 'more than 50 years' category might have severe levels of illness. The difference could also be due to varying levels of awareness about the disease and its treatment process. The patients in the age group of ' 21 35 years' have also been observed to be highly educated in comparison to the patients in age bracket of 'more than 50 years'. 
Table 3: Lists of names, statements, factor loadings and values of Cronbach's alpha for all the factors

\begin{tabular}{|c|c|c|c|}
\hline NAME OF FACTORS & STATEMENTS & $\begin{array}{l}\text { FACTOR } \\
\text { LOADINGS }\end{array}$ & $\begin{array}{l}\text { VALUES OF } \\
\text { CRONBACH'S } \\
\text { ALPHA }\end{array}$ \\
\hline \multirow[b]{5}{*}{ Basic amenities } & Sufficient waiting area & 0.757 & \multirow{5}{*}{0.784} \\
\hline & Approachable medical shop & 0.711 & \\
\hline & Canteen and cafeteria facility & 0.699 & \\
\hline & Provision for the parking vehicles & 0.689 & \\
\hline & Availability of facilities like water, electricity, wash rooms, fans etc. & 0.632 & \\
\hline \multirow{6}{*}{$\begin{array}{l}\text { Reputation and } \\
\text { quality }\end{array}$} & Years of existence of the hospital & 0.795 & \multirow{6}{*}{0.684} \\
\hline & Brand name of the hospital & 0.739 & \\
\hline & Fame of the doctors associated with the hospital & 0.719 & \\
\hline & General image of the hospital in the society & 0.565 & \\
\hline & Quality specialist doctors & 0.511 & \\
\hline & Religious / cultural preference & 0.451 & \\
\hline \multirow{5}{*}{$\begin{array}{l}\text { Building and } \\
\text { infrastructure }\end{array}$} & Latest equipment and facilities in the operation theater & 0.741 & \multirow{5}{*}{0.733} \\
\hline & Modern living room facilities & 0.736 & \\
\hline & Hospital's building and infrastructure & 0.554 & \\
\hline & Number of the rooms and beds & 0.541 & \\
\hline & Availability of latest and hi-tech equipment & 0.493 & \\
\hline \multirow{6}{*}{$\begin{array}{l}\text { Ease and } \\
\text { affordability }\end{array}$} & Proximity of the hospital to your place of residence & 0.811 & \multirow{6}{*}{0.785} \\
\hline & Ease of getting appointments & 0.775 & \\
\hline & Ease of approaching the hospital & 0.735 & \\
\hline & Timing of the OPD services & 0.733 & \\
\hline & Tie up of the hospital with the insurance companies & 0.579 & \\
\hline & Cost of the hospital services & 0.489 & \\
\hline \multirow{4}{*}{$\begin{array}{l}\text { Personal substances } \\
\text { (experiences) }\end{array}$} & Any friend / relative / known who is working in the hospital & 0.841 & \multirow{4}{*}{0.758} \\
\hline & Awareness about disease and its treatment process & 0.825 & \\
\hline & Severity and duration of the illness & 0.618 & \\
\hline & Your previous experience with the hospital & 0.539 & \\
\hline \multirow{4}{*}{$\begin{array}{l}\text { Responsiveness } \\
\text { of services }\end{array}$} & Punctuality and courteous behavior of the nursing staff & 0.841 & \multirow{4}{*}{0.713} \\
\hline & Quick administrative procedures & 0.662 & \\
\hline & Speed in the delivery of services & 0.626 & \\
\hline & Waiting time to get treated & 0.417 & \\
\hline \multirow{3}{*}{$\begin{array}{l}\text { Recommendations } \\
\text { and suggestions }\end{array}$} & Recommendation by your local doctor & 0.799 & \multirow[t]{3}{*}{0.752} \\
\hline & $\begin{array}{l}\text { Recommendation by someone who has already taken the } \\
\text { treatment }\end{array}$ & 0.722 & \\
\hline & Recommendation by your friends/relatives & 0.648 & \\
\hline
\end{tabular}


Table 3: Lists of names, statements, factor loadings and values of Cronbach's alpha for all the factors continued

\begin{tabular}{|l|l|c|c|}
\hline NAME OF FACTORS & STATEMENTS & $\begin{array}{c}\text { FACTOR } \\
\text { LOADINGS }\end{array}$ & $\begin{array}{c}\text { VALUES OF } \\
\text { CRONBACH'S } \\
\text { ALPHA }\end{array}$ \\
\hline \multirow{2}{*}{ Clinical support } & Provision for the ambulance and blood bank & 0.719 & 0.694 \\
\hline \multirow{2}{*}{$\begin{array}{l}\text { Privacy and } \\
\text { information sharing }\end{array}$} & Provision for the laboratories & 0.674 & 0.795 \\
\hline & Availability of service packages like full body checkup etc. & 0.767 & 0.826 \\
& Availability of general health care services & 0.798 & 0.732 \\
& Availability of specialised health care services & 0.646 & 0.652 \\
\hline Range of services & Avaving all the medical departments & 0.481 & 0.448 \\
\hline
\end{tabular}

\section{Gender}

Gender has a positive effect on hospital choice decisions of patients. Roh and Lee [18] have found male respondents to be more concerned about the delivery of services. In this study also, male respondents reported significantly higher importance ( $M S=4.28$ ) with respect to 'responsiveness of services' in comparison to that reported by female respondents $(M S=3.78)$. Male respondents also reported considerably higher importance $(\mathrm{MS}=3.74)$ with respect to 'range of services' in comparison to that reported by female respondents ( $M S=2.94)$. It may be due to a greater concern by the male patients about the available services, time of service delivery and quick administrative procedures. The differences could also be due to higher concern by male respondents about the punctuality of the doctors and staff members, behavior of doctors and staff members, and quality of care provided by nursing staff than that of female respondents.

\section{Residence}

Residence has an important influence on hospital choice decisions of patients. Gesler and Meade [26] and Mheen et al [27] have confirmed that rural area patients are more concerned about the timely delivery of services. Respondents from a 'rural area' in this study, also reported notably higher importance $(M S=4.31)$ with respect to 'responsiveness of services' in comparison to other categories. The respondents from a 'metro city' category have shown relatively lower importance (MS=3.93). The respondents from a 'metro city' have also reported considerably higher importance (MS=4.27) with respect to 'privacy and information sharing' in comparison to other categories. The respondents from a 'non metro city' category showed a relatively lower importance ( $M S=4.01$ ). This may be due to the travel time to receive the treatment. It is quite possible that respondents of 'rural area' do not find it comfortable to have long waiting periods and lengthy administrative procedures compared to the respondents in other categories. The differences could also be due to high awareness level of 'metro city' respondents about the treatment process and confidentiality of complete health records.

\section{Education}

Knowledge, education and awareness about the disease and its treatment process have significant impact on the hospital choice decisions of patients. Lane and Lindquist [5] have studied not only the awareness of educated people for the various dimensions of hospital services, but also the importance of their personal preferences for the hospital selection. It was found that respondents of 'graduation' category in this study reported significantly higher importance (MS=4.52) with respect to 'personal substance (experience)' in comparison to other categories. The respondents of 'class XII or below' category showed relatively lower importance (MS=4.17). It may be due to the awareness about disease and its treatment process and reference of any friend or relative, who is already working in the hospital. The respondents of the 'graduation' category might have more knowledge about the symptoms, reasons and treatment process of the disease. The differences could also be due to the trust of the patients of 'class XII or below' category in a friend or relative who is already working in the hospital. 


\section{Monthly family income}

Monthly family income has a positive influence on the hospital choice decisions of patients. You and Kwon [28] have concluded that middle class patients are more concerned about the availability of basic facilities in the hospitals. Respondents of this study, having monthly family incomes of 'Rs. 25,001 to Rs. 50,000' also reported notably higher importance (MS=3.92) with respect to 'basic amenities' in comparison to other categories. The respondents having monthly family incomes of 'Rs. 50,001 to Rs. 75,000 ' category showed relatively lower importance (MS=3.17). It may be due to availability of basic facilities in the hospital premises. The respondents in the monthly family income group of 'Up to Rs. 25,000 ' and 'Rs. 25,001 to Rs. 50,000' might have more concern about basic facilities like waiting areas, pharmacy, cafeteria, parking, lights, water and fans than the patients of other categories. The difference could also be due to lower concern of the respondents of other categories about basic amenities in the hospital.

\section{Decision-makers involved in the selection of hospitals}

Five categories were observed to be actively engaged in the selection of hospitals. Family members decided in 49.6 percent of cases, doctors decided in 12.3 percent of cases, family members and doctors together decided in 19.5 percent of cases, friends/relatives decided in 10.4 percent of cases, and patients themselves decided in 8.2 percent of cases. Previous studies have also presented the similar findings. [15] Table 4 shows the decision-makers involved in the selection of hospitals.

\section{Conclusion and implications}

The results of this study revealed that the ten factors affecting hospital choice decisions of patients are: basic amenities, reputation and quality, building and infrastructure, ease and affordability, personal substances (experiences), responsiveness of services, recommendations and suggestions, clinical support, privacy and information sharing and range of services. It was found that statistically significant differences $(P<.05)$ exist among the various categories of respondent demographics with respect to these factors. These differences were observed among the various categories of age, gender, residence, education and monthly family income, with respect to the factors, namely, 'personal substance (experience)', 'responsiveness of services' and 'range of services', 'responsiveness of services' and 'privacy and information sharing', 'personal substance (experience)' and 'basic amenities, respectively. It was also found that family members, doctors, family members and doctors together, friends/relatives and patients themselves chose the hospitals for the treatment. Various other studies have also reported these findings. $[6,18,19]$

These results have implications for healthcare organisations' marketing and policy formulations. They can be used by healthcare organisations, doctors and other healthcare professionals to improve the quality of services. In addition, this study is expected to make a meaningful contribution to the literature on healthcare marketing. Researchers may also benefit from this study while undertaking similar studies in future.

\section{Limitations and future research}

One limitation of this study is that it has been conducted in north India. Though the results concur with other studies conducted in other countries, future research could examine the factors affecting hospital choice decisions of patients from different parts of the world. Another limitation is that the study has been conducted with a limited number of respondents using convenience sampling methods. Future research could look at increasing the sample size or using other methods of sampling to gain more insight into the factors affecting hospital choice decisions. Additionally, the researchers could attempt to explore more factors in this regard and a disease-wise analysis could also be carried out to further understand the factors which affect hospital choice decisions of patients for tertiary level health diseases.

Table 4: Decision-makers involved in the selection of hospitals

\begin{tabular}{|l|c|c|}
\hline DECISION-MAKERS & NUMBER OF CASES (N=883) & PERCENTAGE (\%) \\
\hline Family members & 438 & 12.3 \\
\hline Doctors & 109 & 19.5 \\
\hline Doctors and family members & 172 & 10.4 \\
\hline Friends and relatives & 92 & 12.6 \\
\hline
\end{tabular}




\section{Competing interests}

The authors declare that they have no competing interests.

\section{References}

1. Schiffman L, David B, Aron O, Angela P, Leslie K. Consumer behaviour, 3rd Edition. Frenchs Forest, NSW: Pearson Education; 2005.

2. Gensch DH, Javalgi RG. The influence of involvement on disaggregate choice models. Journal of Consumer Research. 1987;14(June):71-82.

3. Brent CM. International patterns of consumer behavior. In: Mary Jane Schlinger, editor. Advance consumer research, Volume 2 (ed). Association for Consumer Research; 1975. p. 93-103.

4. Mishra PH, Mishra T. Study of patient satisfaction at a super specialty tertiary care Hospital. Indian Journal of Clinical Practice. 2014;25(7):624-634.

5. Lane PM, Lindquist JD. Hospital choice: a summary of the key empirical and hypothetical findings of the 1980s. J Health Care Mark. 1988;8(4):5-20.

6. Bahrami MA, Jannati A, Gholizadeh M, Alizadeh L, Khodayari MT. A survey of factors affecting patients' decision in selecting governmental and private hospitals in Tabriz, Iran. Journal of Tourism Research and Hospitality. 2013;2(1):1-4.

7. Verma DS, Khandelwal U. Consumers' preferences towards service industry: a factorial study of health care industry. International Journal of Multidisciplinary Research. 2011;1(8):83-89.

8. Berkowitz EN, Flexner W. The market for health services: is there a non-traditional consumer? J Health Care Mark. 1980;1(1):25-34.

9. Boscarino, Joseph, Steiber SR. Hospital shopping and consumer choice. J Health Care Mark. 1982;2(2):23-25.

10. Egunjobi L. Factors influencing choice of hospitals: a case study of the northern part of Oyo State, Nigeria. Soc Sci Med. 1983; 17(9):585-589.

11. Wolinsky FD, Kurz RS. How the public chooses and views hospitals. Hospital and Health Services Administration. 1984;29(6):58-67.

12. Bin SK. Factors affecting patient's choice of hospitals. Ann Saudi Med. 1997;18(5):420-424.

13. Keaveney SM. Customer switching behavior in service industries: an exploratory study. The Journal of Marketing. 1995;59(2):71-82.

14. Hanna N, Schoenbachler DD, Gordon GL. Physician choice criteria: factors influencing patient selection of generalists versus specialists. Health Mark Q. 1994;12(2):29-42.

15. Akinci F, Esatoglu AE, Tengilimoglu D, Parsons A. Hospital choice factors: a case study in Turkey. Health Mark Q. 2005;22(1):3-19.

16. Bhangale V. Marketing of healthcare services in India: a study on factors influencing patients' decision making on choice of a hospital. J Manag Marketing Healthc. 2011;4(4):229-233.

17. Borah BJ. A mixed logit model of health care provider choice: analysis of NSS data for rural India. Health Economics. 2006; 15(9):915-932.

18. Roh CY, Lee KH. Hospital choice by rural Medicare beneficiaries: does hospital ownership matter? - A Colorado case. J Health Hum Serv Adm. 2005;28(3):346-365

19. Vonberg RP, Sander C, Gastmeier P. Consumer attitudes about health care - acquired infections: A German survey on factors considered important in the choice of a hospital. Am J Med Qual. 2008;23(1):56-59.

20. Dubey P, Sharma SK. Factors affecting choice of hospital services in bilaspur city. Abhinav: International Monthly Refereed Journal of Research In Management and Technology. 2013;2(April):97-104

21. Ngondi BW. Factors influencing access to health care services among cervical cancer patients at Kenyatta national hospital [Doctoral dissertation]. University of Nairobi; 2014.
22. Jackson B, Jensen J. Cost issues. National consumer study (Lincoln NE). Nebraska: National Research Corporation; 1985.

23. Smith SM, Clark M. Hospital image and the positioning of service centers: an application in market analysis and strategy development. J Health Care Mark. 1990;10(3):13-22.

24. Daloglu, G. Özel hastaneyi kullananlarn tercih nedenleri ve seçilen hastalk gruplarindaki ortalama yatis süresi. Hacettepe Üniversitesi Saglik Bilimleri Enstitüsü Yayinlanmamis Yüksek Lisans Tezi, Ankara; 1991. (In Turkish).

25. Korgaonkar PK, Lund D, Price B. A structural equations approach toward examination of store attitude and store patronage behavior. Journal of Retailing. 1985;61(2):39-60.

26. Gesler WM, Meade MS. Locational and population factors in health care-seeking behavior in Savannah, Georgia. Health Services Research. 1988;23(3):443-462.

27. Mheen PJM et al. The relative importance of quality of care information when choosing a hospital for surgical treatment a hospital choice experiment. Med Decis Making. 2011; 31(6):816-827.

28. You $\mathrm{CH}$, Kwon YD. Factors influencing medical institution selection for outpatient services. Journal of the Korean Medical Association. 2012;55(9):898-910 